\title{
Impact of Statin Use and Lipid Profile on Symptomatic Intracerebral Haemorrhage, Outcome and Mortality after Intravenous Thrombolysis in Acute Stroke
}

\author{
Andrea Rocco ${ }^{a}$ Marek Sykora ${ }^{a}$ b Peter Ringleb $^{a}$ Jennifer Diedler ${ }^{a}$ \\ a Department of Neurology, University of Heidelberg, Heidelberg, Germany; ${ }^{b}$ Department of Neurology, \\ Comenius University, Bratislava, Slovakia
}

\author{
Key Words \\ Cholesterol $\cdot$ Statins $\cdot$ Ischaemic stroke $\cdot$ Thrombolysis • \\ Haemorrhage
}

\begin{abstract}
Background: It is unclear if a certain lipid profile and/or statin use contribute to symptomatic intracerebral haemorrhage $(\mathrm{s} \mid \mathrm{CH})$, poor outcome or mortality after intravenous thrombolysis for ischaemic stroke. The aim of the current study was to assess the impact of statin use and lipid profile on $\mathrm{sICH}$, outcome and mortality following thrombolysis in acute stroke. Methods: From 2001 to 2010, all patients admitted to our hospital and undergoing intravenous thrombolysis for acute ischaemic stroke were included into an open, prospective database. Initial stroke severity was assessed using the National Institute of Health Stroke Scale. Demographics, vascular risk factors, admission blood pressure, glucose levels, previous medication including statin use, lipid profiles including low-density lipoprotein (LDL), high-density lipoprotein (HDL) and triglyceride levels were recorded. Outcome measures included $\mathrm{sICH}$ according to the European Cooperative Acute Stroke Study II criteria, modified Rankin scale and mortality at 3 months. Results: 1,066 patients were included in the analysis; $5.3 \%$ (57 patients) had sICH. Mortality at 3 months was $17.6 \%$ (188 patients). A favourable outcome (modified Rankin scale 0-1) at
\end{abstract}

3 months was attained by $35.6 \%$ (379 patients). Prior statin use was not associated with increased odds for sICH (OR 1.05, $95 \% \mathrm{Cl} 0.55-2.04, \mathrm{p}=0.864$ ), mortality (OR $1.32,95 \% \mathrm{Cl} 0.90$ $1.93, \mathrm{p}=0.152$ ) or favourable outcome (OR $0.89,95 \% \mathrm{Cl} 0.65$ $1.24, p=0.507)$. Similar results were found for the different lipid variables: high LDL (OR 0.96, 95\% Cl 0.36-2.60, $p=$ $0.942)$, high triglyceride (OR $1.74,95 \% \mathrm{Cl} 0.84-3.56, \mathrm{p}=0.132$ ) and low HDL (OR 1.78, 95\% Cl 0.68-4.65, $\mathrm{p}=0.279$ ) were not associated with increased odds for $\mathrm{sICH}$. Likewise, neither mortality nor functional outcome at 3 months was significantly associated with any of the lipid variables in the univariable analysis following Bonferroni adjustment for multiple comparisons. The same results were found in the multivariable analysis adjusting for imbalances in baseline characteristics. Conclusions: In contrast to previous studies, we found that in stroke patients receiving thrombolysis therapy, neither the lipid profile nor prior statin use were associated with increased odds for $\mathrm{sICH}$, functional outcome or mortality at 3 months.

Copyright $\odot 2012$ S. Karger AG, Basel

\section{Introduction}

Intracerebral haemorrhage (ICH) is one of the most feared complications after thrombolytic therapy in stroke patients. Depending on the definition, it occurs in ap-

\section{KARGER \\ Fax +4161306 1234 \\ E-Mail karger@karger.ch}

www.karger.com (c) 2012 S. Karger AG, Basel

$1015-9770 / 12 / 0334-0362 \$ 38.00 / 0$

Accessible online at:

www.karger.com/ced
Andrea Rocco, MD

Department of Neurology, University of Heidelberg

Im Neuenheimer Feld 400

DE-69120 Heidelberg (Germany)

Tel. +496221563 7540, E-Mail Andrea.Rocco@med.uni-heidelberg.de 
proximately $6 \%$ of patients and is associated with a poor outcome [1]. Different factors, such as the presence of early hypodensity on CT, elevated serum glucose, history of diabetes, increased time to treatment, higher pre-treatment blood pressure, lower platelet count and history of cardiac disease, have been suggested as predictors of ICH after thrombolysis [2].

However, the role of the lipid profile and prior statin use for the occurrence of symptomatic ICH (sICH) following intravenous thrombolysis and their implications for the outcome remain unclear. While the protective role of hydroxymethylglutaryl-CoA reductase inhibitors (statins) in first-ever and recurrent ischaemic strokes is clearly proven [3], some authors also report statin use to be associated with favourable functional outcome following thrombolysis [4], and others identified statin medication and low low-density lipoprotein (LDL) as risk factors for thrombolysis-related haemorrhages $[5,6]$. However, the data remain controversial as some studies only identified high-admission triglyceride levels as a risk factor for sICH, but not LDL levels or statin therapy [7]. Finally, other authors report that the use of statins or hypercholesterolaemia before first-ever ischaemic stroke is associated with a better early outcome, while statin therapy may increase the risk of ICH [8].

The present study aims to investigate the role of the lipid profile and statin use prior to intravenous thrombolytic therapy for acute ischaemic stroke patients in the occurrence of sICH based on our local thrombolysis database including 1,066 patients, employing two different definitions of ICH. Furthermore, the impact on functional outcome and mortality was assessed.

\section{Methods}

\section{Patients}

From 2001 to 2010 (cut-off point of the current analysis: 19 November 2010), all patients admitted to our hospital and undergoing intravenous thrombolysis for acute ischaemic stroke were included into an open, prospective database. Initial stroke severity was assessed using the National Institute of Health Stroke Scale (NIHSS) by a trained neurologist. Demographics, vascular risk factors, admission blood pressure, glucose levels, and previous medication including statin use were recorded. Lipid profiles were assessed as fasting values the morning following admission, including LDL, high-density lipoprotein (HDL), LDL/HDL ratio and triglyceride levels. Patients underwent a non-contrast brain CT scan before treatment and a routine brain CT scan 24-36 h after thrombolysis. Stroke subtypes were classified according to the TOAST classification: (1) large-artery atherosclerosis, (2) cardioembolism, (3) small-artery occlusion (lacunar), (4) stroke of other determined aetiology, and (5) stroke of undetermined aetiology [9].

Impact of Statin Use/Lipid Profile on

sICH, Outcome and Mortality

\section{Outcome Parameters}

Outcome parameters included the occurrence of sICH within $36 \mathrm{~h}$ following thrombolysis, the occurrence of any ICH, mortality at 3 months and functional outcome at 3 months. sICH was assessed using the slightly modified European Cooperative Acute Stroke Study (ECASS II) criteria (any haemorrhage with neurological deterioration, as indicated by an NIHSS score $\geq 4$ points higher than the value at baseline, or any haemorrhage leading to death). Any ICH was defined as any blood on the follow-up CT scan within $36 \mathrm{~h}$ following thrombolysis. Functional outcome was assessed upon discharge and in the 90 days of follow-up and was measured by the modified Rankin scale (mRS) score. Favourable outcome was defined as an mRS score of $0-1$.

\section{Statistical Analysis}

Baseline variables were compared using Pearson's $\chi^{2}$ and the Mann-Whitney $U$ tests where appropriate. For categorical variables, percentage proportions were calculated by dividing the number of events by the total number of patients, excluding missing or unknown cases. Analogously, median and interquartile ranges were calculated for continuous variables, leaving out missing or unknown cases.

Based on the literature [3-7], low LDL levels, low HDL levels, high triglyceride levels and a high LDL/HDL ratio were considered risk factors for sICH, mortality and outcome. For further analyses, the population was thus grouped according to (1) statin use, (2) high versus low LDL levels, (3) high versus low HDL levels, (4) high versus low triglyceride levels, and (5) high versus low $\mathrm{LDL} / \mathrm{HDL}$ ratio. For LDL, the cut-off of $100 \mathrm{mg} / \mathrm{dl}$ was chosen according to current guidelines [10]. Since no thresholds for HDL, triglycerides and the LDL/HDL ratio have been reported in the literature, the population was split using the 25th (for HDL) and 75th (for triglycerides and LDL/HDL ratio) percentiles as cut-off values. Odds ratios were calculated using $2 \times 2$ cross-tables. Adjusted odds ratios were calculated using logistic regression models including age, gender, baseline NIHSS, hypertension, diabetes, atrial fibrillation, systolic and diastolic blood pressure, glucose level on admission, and stroke aetiology. All statistical analyses were performed using the SPSS software (version 16.0). Following Bonferroni adjustment for multiple comparisons, only $\mathrm{p}$ values $<0.01$ were considered significant.

\section{Results}

In total, 1,066 patients were registered in our local thrombolysis database. Baseline characteristics are listed in table 1.

sICH according to ECASS II criteria occurred in 57 patients (5.3\%), while any ICH on the post-treatment CT scan was found in 186 patients (17.4\%). Overall mortality at 3 months was $17.6 \%$ (188 patients). A favourable outcome (mRS $0-1)$ at 3 months was reached by 379 patients (35.6\%). The number of patients with prior statin medication were equally distributed in patients with or without haemorrhages (table 1). Likewise, there was no significant difference in median LDL, HDL or triglyceride levels and 
Table 1. Baseline characteristics

\begin{tabular}{|c|c|c|c|c|c|c|c|}
\hline & $\begin{array}{l}\text { Total } \\
(\mathrm{n}=1,066)\end{array}$ & \multicolumn{3}{|l|}{ sICH } & \multicolumn{3}{|l|}{ Any ICH } \\
\hline Male sex & $563 / 1,066(52.8)$ & $22 / 57(38.6)$ & $541 / 1,009(53.6)$ & $0.027^{2}$ & $86 / 186(46.2)$ & $477 / 880(54.2)$ & $0.048^{1}$ \\
\hline Hypertension & $832 / 1,063(78.3)$ & $51 / 57(89.5)$ & $781 / 1,006(77.6)$ & $0.035^{2}$ & $152 / 186(81.7)$ & $680 / 877(77.5)$ & $0.209^{1}$ \\
\hline Diabetes & $276 / 1,063(26.0)$ & $22 / 57(38.6)$ & $254 / 1,005(25.3)$ & $0.026^{2}$ & $57 / 186(30.6)$ & $219 / 876(25.0)$ & $0.111^{1}$ \\
\hline \multicolumn{8}{|l|}{ TOAST } \\
\hline Large-artery atherosclerosis & 206/1,066 (19.3) & 4/57 (7.0) & $202 / 1,009(20.0)$ & & $23 / 186(12.4)$ & $183 / 880(20.8)$ & \\
\hline Cardioembolism & $547 / 1,066(51.3)$ & $36 / 57(63.2)$ & $511 / 1,009(50.6)$ & & $123 / 186(66.1)$ & $424 / 880(48.2)$ & \\
\hline Small-artery occlusion & $44 / 1,066(4.1)$ & $0 / 57(0)$ & $44 / 1,009(4.4)$ & $0.040^{2}$ & $1 / 186(0.5)$ & $43 / 880(4.9)$ & $<0.001^{1}$ \\
\hline Other & $31 / 1,066(2.9)$ & $1 / 57(1.8)$ & $30 / 1,009(3.0)$ & & $4 / 186(2.2)$ & $27 / 880(3.1)$ & \\
\hline Unknown & $238 / 1,066(22.3)$ & $16 / 57(28.1)$ & $222 / 1,009(22.0)$ & & $35 / 186(18.8)$ & $203 / 880(23.1)$ & \\
\hline LDL & $115[48] / 662$ & $114[64] / 18$ & $115[48] / 644$ & $0.981^{1}$ & $110[47] / 97$ & $116[47] / 565$ & $0.079^{2}$ \\
\hline HDL & $44[16] / 670$ & $39[21.3] / 18$ & $44[17] / 652$ & $0.081^{1}$ & $44[17] / 98$ & $44[17] / 572$ & $0.400^{2}$ \\
\hline Triglycerides & $103[69] / 885$ & $101[83] / 33$ & $103[69] / 852$ & $0.705^{1}$ & $95[61] / 146$ & $104[71] / 739$ & $0.070^{2}$ \\
\hline LDL/HDL & $2.7[1.3] / 662$ & $3.0[1.1] / 18$ & $2.6[1.3] / 644$ & $0.065^{1}$ & $2.5[1.3] / 97$ & $2.7[1.3] / 565$ & $0.561^{2}$ \\
\hline Systolic BP & $160[31] / 859$ & $150[30] / 45$ & $160[31] / 814$ & $0.429^{1}$ & $157[28] / 160$ & $160[31] / 699$ & $0.082^{2}$ \\
\hline Diastolic BP & $87[17] / 855$ & $84[18] / 44$ & $87[17] / 811$ & $0.210^{1}$ & $86[22] / 159$ & $87[16] / 696$ & $0.678^{2}$ \\
\hline Glucose & $122[44] / 1,062$ & $132[48] / 57$ & $121[43] / 1,005$ & $0.106^{1}$ & $125[47] / 186$ & $121[43] / 876$ & $0.019^{2}$ \\
\hline
\end{tabular}

the LDL/HDL ratio between patients with or without $\mathrm{ICH}$, regardless of the definition (table 1).

According to the literature, prior statin use, low LDL, low HDL and high triglyceride levels, as well as a high $\mathrm{LDL} / \mathrm{HDL}$ ratio were defined as risk factors for $\mathrm{sICH}$, mortality or unfavourable outcome. So far, no definite thresholds have been published. Therefore, in an exploratory approach, we defined low or high values according to the 25th and 75th percentiles in our population.

Prior statin use was not associated with significantly increased odds for sICH according to ECASS II (OR 1.05, 95\% CI 0.55-2.04, $\mathrm{p}=0.864)$, any ICH (OR 1.35, 95\% CI $0.92-1.96, \mathrm{p}=0.122$ ), mortality (OR $1.32,95 \%$ CI $0.90-$ $1.93, \mathrm{p}=0.152)$ or decreased odds for favourable outcome (OR 0.89, 95\% CI 0.65-1.24, $\mathrm{p}=0.507$; table 2).

Similar results were found for all lipid variables including low LDL ( $\leq 100 \mathrm{mg} / \mathrm{dl})$, low HDL ( $\leq 36 \mathrm{mg} / \mathrm{dl}$ ), high triglycerides $(\geq 144 \mathrm{mg} / \mathrm{dl})$ and high LDL/HDL ratios ( $\geq 3.33$ ) (table 2). Of note, the Bonferroni adjustment was applied to correct for multiple comparisons, and thus, only $\mathrm{p}$ values $<0.01$ were considered significant.

Table 3 shows the multivariate analysis. As in the univariate analysis, after adjustment for baseline characteristics, neither prior statin use nor any of the lipid variables were associated with significantly increased odds for sICH, mortality or decreased odds for favourable functional outcome at 3 months. Although LDL levels below the 25th percentile were associated with a slightly increased risk of mortality (OR 1.82, 95\% CI 1.01-3.29, p = 0.047), the result was not considered significant applying Bonfer roni adjustment for multiple comparisons, requiring a $\mathrm{p}$ value $<0.01$.

\section{Discussion}

Based on our local thrombolysis database including a total of 1,066 patients, we found neither previous statin therapy nor the lipid profile to be associated with the oc- 


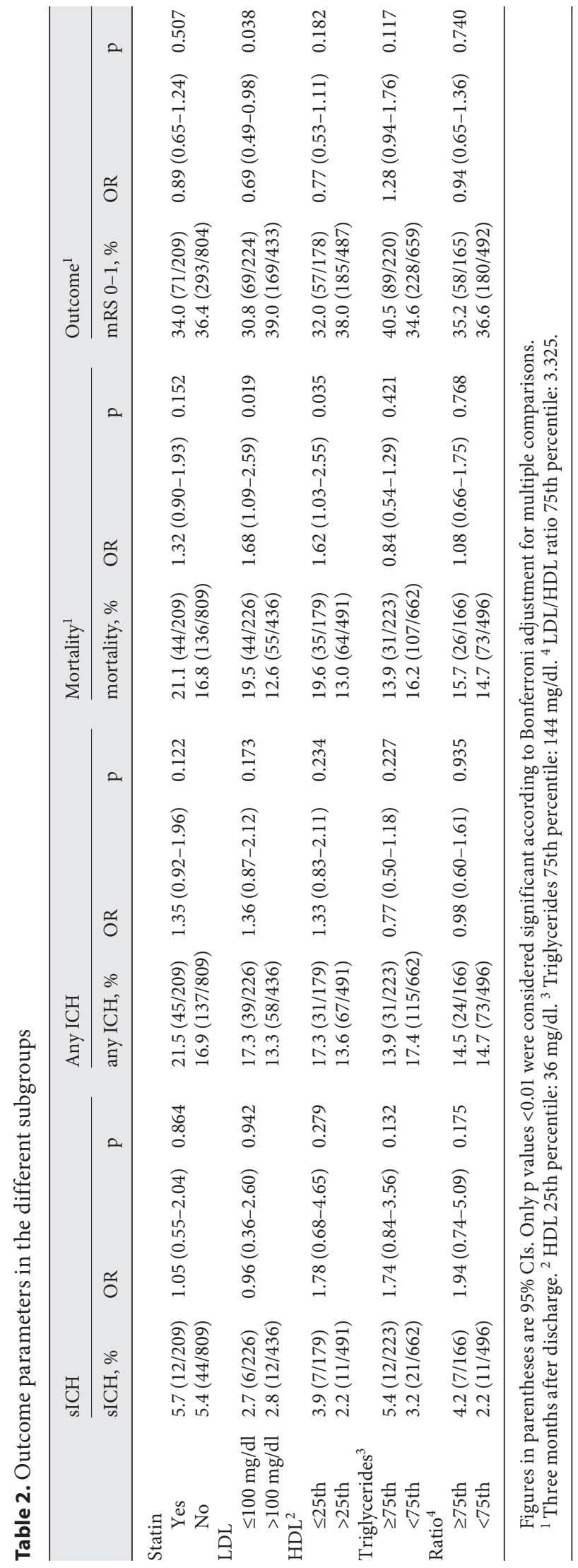

Impact of Statin Use/Lipid Profile on sICH, Outcome and Mortality currence of thrombolysis-related ICH as described in previous studies [5-7, 11-13], regardless of the definition used for ICH. The same was found for mortality or functional outcome at 3 months.

These findings are in contrast to previous studies, which report concerning results about lipid profiles and statin use as risk factors for thrombolysis-related ICH (for an overview, see table 4).

Bang et al. [6] analyzed 104 patients receiving intravenous or intra-arterial thrombolysis with tissue plasminogen activator (tPA), including mechanical recanalization. In their study, lower LDL cholesterol levels upon admission but not prior statin use were found to be independently associated with sICH. In contrast, Uyttenboogaart et al. [7] including a population of 252 patients treated with intravenous tPA for acute ischaemic stroke only identified high triglyceride levels but not low LDL or prior statin as risk factors for sICH. Two other studies finally reported the use of lipid-lowering medication as an independent risk factor for sICH following thrombolysis $[5,12]$.

In contrast to these studies - and in line with our results - the report of Montaner [14] showed a lack of association between previous statin use or the lipid profile with sICH among recombinant tPA-treated patients. However, the sample size was relatively small, including only lipid profiles - in contrast to other studies assessed in the hyperacute phase - from 60 patients; the results on prior statin use were based on 145 patients. Furthermore, a recent case-control study including 182 patients showed no significant difference in the incidence of sICH in patients with versus in those without statin pre-treatment (3.3 vs. $1.7 \% ; p=0.47$ ) [15]. Likewise, there was no difference between the two groups with respect to favourable short-term ( 44.8 vs. $56 \%$; $\mathrm{p}=0.31$ ) or long-term outcome ( 40 vs. $44.1 \% ; \mathrm{p}=0.84$ ). In contrast, in a meta-analysis provided in the same paper including 1,055 patients, statin pre-treatment was neither related to long-term functional outcome nor to mortality, but was shown to be a risk factor for $\mathrm{sICH}(\mathrm{OR} 1.99,95 \%$ CI 1.03-3.84, $\mathrm{p}=$ 0.04) [15].

The heterogeneity in the previous studies may be due to several reasons. Firstly, they included a heterogeneous population undergoing different treatment modalities, including mechanical recanalization [6] and intra-arterial urokinase [5]. Second, all studies except for one [7] investigated only partial aspects, for instance providing data on statin use $[8,12]$ but not reporting lipid profiles, or providing data on sICH but not on functional outcomes $[6,8]$. Furthermore, sample sizes in most of these 
Table 3. Adjusted ORs for the different outcome parameters

\begin{tabular}{|c|c|c|c|c|c|c|c|c|}
\hline & \multicolumn{2}{|l|}{$\mathrm{sICH}$} & \multicolumn{2}{|l|}{ Any ICH } & \multicolumn{2}{|l|}{ Mortality $^{1}$} & \multicolumn{2}{|c|}{ Outcome (mRS $0-1)^{1}$} \\
\hline & OR & $\mathrm{p}$ & OR & $\mathrm{p}$ & OR & $\mathrm{p}$ & OR & $\mathrm{p}$ \\
\hline Statin & $1.18(0.56-2.48)$ & 0.669 & $1.21(0.79-1.8)$ & 0.379 & $1.32(0.82-2.10)$ & 0.249 & $1.14(0.76-1.73)$ & 0.525 \\
\hline $\mathrm{LDL} \leq 100 \mathrm{mg} / \mathrm{dl}$ & $0.77(0.26-2.24)$ & 0.625 & $1.21(0.75-1.96)$ & 0.429 & $1.12(0.68-1.99)$ & 0.576 & $0.99(0.65-1.53)$ & 0.971 \\
\hline $\mathrm{HDL} \leq 25$ th & $1.85(0.64-5.37)$ & 0.257 & $1.27(0.75-2.13)$ & 0.370 & $1.82(1.01-3.29)$ & 0.047 & $0.74(0.45-1.17)$ & 0.200 \\
\hline Triglycerides $\geq 75$ th & $1.69(0.77-3.73)$ & 0.192 & $0.83(0.52-1.32)$ & 0.434 & $1.33(0.78-2.26)$ & 0.293 & $1.19(0.79-1.77)$ & 0.500 \\
\hline Ratio $\geq 75$ th & $1.75(0.62-5.04)$ & 0.289 & $0.99(0.57-1.69)$ & 0.969 & $1.29(0.70-2.38)$ & 0.421 & $0.74(0.46-1.81)$ & 0.206 \\
\hline
\end{tabular}

ORs are adjusted for age, sex, baseline NIHSS, hypertension, diabetes, atrial fibrillation, systolic and diastolic blood pressure, glucose, and TOAST criteria using a logistic regression model. Figures in parentheses are 95\% CIs. Only p values $<0.01$ were considered significant according to Bonferroni adjustment for multiple comparisons.

${ }^{1}$ Three months after discharge.

Table 4. Overview of selected previous studies on the association between lipid profiles and sICH and outcome

\begin{tabular}{|c|c|c|c|c|c|c|}
\hline Reference & $\begin{array}{l}\text { Cohort/ } \\
\text { treatment }\end{array}$ & Variables & sICH rate, $\%$ & sICH definition & $\begin{array}{l}\text { Independent } \\
\text { risk for sICH }\end{array}$ & Outcome \\
\hline $\begin{array}{l}\text { Bang } \\
\text { et al. [6], } 2007\end{array}$ & $\begin{array}{l}104 \text { patients } \\
\text { IV or IA rtPA, } \\
\text { mechanical or } \\
\text { combined }\end{array}$ & $\begin{array}{l}\text { total cholesterol, } \\
\text { LDL, HDL and } \\
\text { triglycerides }\end{array}$ & 16.3 & $\begin{array}{l}\text { any clinical worsening } \\
\text { associated with HT in } \\
\text { CT scan }\end{array}$ & $\begin{array}{l}\text { 1. NIHSS } \\
\text { 2. low LDL } \\
\text { 3. current smoking }\end{array}$ & not reported \\
\hline $\begin{array}{l}\text { Montaner [14], } \\
2008^{1}\end{array}$ & $\begin{array}{l}60 \text { patients } \\
\text { (lipid profiles) } \\
145 \text { patients } \\
\text { (statin use) } \\
\text { IV rtPA }\end{array}$ & $\begin{array}{l}\text { total cholesterol, } \\
\text { LDL, HDL and } \\
\text { triglycerides }\end{array}$ & $\begin{array}{l}8.3 \text { (of } 60 \text { patients } \\
\text { with lipid profiles); } \\
8.3 \text { (statins) versus } \\
9.3 \text { (no statins) }\end{array}$ & not reported & $\begin{array}{l}\text { lipid profile and } \\
\text { statins not associated } \\
\text { with sICH; } \\
\text { predictors for sICH } \\
\text { not reported }\end{array}$ & $\begin{array}{l}\text { not reported (for lipid } \\
\text { profile), statin use } \\
\text { predictor for good } \\
\text { functional outcome }\end{array}$ \\
\hline $\begin{array}{l}\text { Uyttenboogard } \\
\text { et al. [7], } 2008\end{array}$ & $\begin{array}{l}252 \text { patients } \\
\text { IV rtPA }\end{array}$ & $\begin{array}{l}\text { total cholesterol, } \\
\text { LDL, HDL and } \\
\text { triglycerides }\end{array}$ & 5.2 & $\begin{array}{l}\text { neurological deteriora- } \\
\text { tion within } 48 \mathrm{~h} \text { follow- } \\
\text { ing rtPA treatment with } \\
\text { HT in CT scan }\end{array}$ & $\begin{array}{l}\text { 1. serum glucose } \\
\text { 2. NIHSS } \\
\text { 3. anti-platelets } \\
\text { 4. high triglycerides }\end{array}$ & $\begin{array}{l}\text { lipid profile and statins } \\
\text { not associated with } \\
\text { favourable outcome at } \\
3 \text { months }\end{array}$ \\
\hline $\begin{array}{l}\text { Meier } \\
\text { et al. [5], } 2009\end{array}$ & $\begin{array}{l}311 \text { patients } \\
\text { IA urokinase }\end{array}$ & $\begin{array}{l}\text { total cholesterol, } \\
\text { LDL, HDL and } \\
\text { triglycerides }\end{array}$ & 4.8 & $\begin{array}{l}\mathrm{PH} 2 \text { with clinical } \\
\text { worsening of NIHSS } \\
\text { scale } \geq 4\end{array}$ & $\begin{array}{l}\text { 1. prior statin use } \\
\text { 2. NIHSS } \\
\text { 3. atrial fibrillation } \\
\text { 4. worse collaterals }\end{array}$ & $\begin{array}{l}\text { lipid profile and statins } \\
\text { not associated with } \\
\text { clinical outcome at } \\
3 \text { months }\end{array}$ \\
\hline $\begin{array}{l}\text { Miedema } \\
\text { et al. [13], } 2010\end{array}$ & $\begin{array}{l}476 \text { patients } \\
\text { IV rtPA }\end{array}$ & $\begin{array}{l}\text { total cholesterol } \\
\text { and LDL }\end{array}$ & 5.8 & SITS-MOST criteria & not reported & $\begin{array}{l}\text { lipid profile not } \\
\text { associated with } \\
\text { favourable outcome }\end{array}$ \\
\hline $\begin{array}{l}\text { Martinez-Ramirez } \\
\text { et al. [15], } 2011\end{array}$ & $\begin{array}{l}182 \text { patients } \\
\text { IV rtPA }\end{array}$ & $\begin{array}{l}\text { statin use before } \\
\text { stroke, hyper- } \\
\text { cholesterolaemia }\end{array}$ & 2.2 & SITS-MOST criteria & not reported & $\begin{array}{l}\text { no differences between } \\
\text { prior statin use and no } \\
\text { statin use regarding } \\
\text { sICH or outcome }\end{array}$ \\
\hline
\end{tabular}

IV = Intravenous; IA = intra-arterial; HT = haemorrhagic transformation; BP = blood pressure; PH2 = parenchymal haemorrhage type 2; SITSMOST $=$ Safe Implementation of Thrombolysis in Stroke-Monitoring Study.

${ }^{1}$ Lipids were measured in the hyperacute phase of stroke $(<3 \mathrm{~h})$ 
studies were relatively small, ranging between 60 and 510 patients (table 4), resulting in wide 95\% CIs. Unfortunately, the by far largest registry of thrombolytic therapy in stroke patients (SITS-ISTR) did not collect information about statin pre-treatment or cholesterol subgroups up to 2011. Thus, for an analysis of the influence of the lipid profile and lipid-lowering drugs, single or oligo-centre registries have to be used.

Furthermore, with respect to sICH, the influence of the sICH definition has to be taken into account, since frequencies and risk factors may vary widely depending on the definition used [16]. In our study, lipid profiles or statin therapy were not associated with thrombolysis-related $\mathrm{ICH}$, regardless of the definition used.

Our study included the so far largest population, providing data on lipid profiles, statin pre-treatment and different outcome parameters, but nevertheless has some limitations. Firstly, although the lipid profile was performed in a 12- to 24-hour fasting status, lipid levels in the acute phase of stroke may decrease. However, we aimed to determine the relation between admission lipid levels and prior statin use in acute thrombolyzed patients. Secondly, the retrospective character of our study and the non-blinded follow-up data collection could lead to a possible bias. Especially, since lipid profiles were not avail- able for the entire population (LDL for 62.1\%, HDL 62.9\% and triglyceride $83.0 \%$ ) and the baseline characteristics between those with versus those without LDL levels available differed significantly (see online suppl. table 1, www. karger.com/doi/10.1159/000335840). However, data on statin use were available for $95.5 \%$ of the population. Finally, data on pre-stroke mRS were not available, which may bias our outcome analysis since $17.9 \%$ of our patients had a history of previous stroke.

In summary, in contrast to previous studies, neither prior statin use nor the lipid profile were associated with sICH or any of the outcome parameters in patients undergoing thrombolysis for acute ischaemic stroke. An ongoing multi-centric, randomized, double-blind clinical trial now aims to evaluate the use of simvastatin in the acute phase of ischaemic stroke with respect to functional outcome and its association to haemorrhagic transformation [17]. This trial may help give a final answer to the question of statin use in patients undergoing thrombolysis for acute stroke.

\section{Disclosure Statement}

No conflict of interest.

\section{References}

1 Tissue plasminogen activator for acute ischemic stroke. The National Institute of Neurological Disorders and Stroke rt-PA Stroke Study Group. N Engl J Med 1995;333: 1581-1587.

2 Hacke W, Kaste M, Fieschi C, von Kummer R, Davalos A, Meier D, Larrue V, Bluhmki E, Davis S, Donnan G, Schneider D, Diez-Tejedor E, Trouillas P: Randomised double-blind placebo-controlled trial of thrombolytic therapy with intravenous alteplase in acute ischaemic stroke (ECASS II). Second European-Australasian Acute Stroke Study Investigators. Lancet 1998;352:1245-1251.

- 3 Amarenco P, Labreuche J, Lavallee P, Touboul PJ: Statins in stroke prevention and carotid atherosclerosis: systematic review and up-to-date meta-analysis. Stroke 2004;35: 2902-2909.

-4 Alvarez-Sabin J, Huertas R, Quintana M, Rubiera M, Delgado P, Ribo M, Molina CA, Montaner J: Prior statin use may be associated with improved stroke outcome after tissue plasminogen activator. Stroke 2007;38: 1076-1078.
5 Meier N, Nedeltchev K, Brekenfeld C, Galimanis A, Fischer U, Findling O, Remonda L, Schroth G, Mattle HP, Arnold M: Prior statin use, intracranial hemorrhage, and outcome after intra-arterial thrombolysis for acute ischemic stroke. Stroke 2009;40:1729-1737.

6 Bang OY, Saver JL, Liebeskind DS, Starkman S, Villablanca P, Salamon N, Buck B, Ali L, Restrepo L, Vinuela F, Duckwiler G, Jahan R, Razinia T, Ovbiagele B: Cholesterol level and symptomatic hemorrhagic transformation after ischemic stroke thrombolysis. Neurology 2007;68:737-742.

7 Uyttenboogaart M, Koch MW, Koopman K, Vroomen PC, Luijckx GJ, De Keyser J: Lipid profile, statin use, and outcome after intravenous thrombolysis for acute ischaemic stroke. J Neurol 2008;255:875-880.

-8 Arboix A, Garcia-Eroles L, Oliveres M, Targa C, Balcells M, Massons J: Pretreatment with statins improves early outcome in patients with first-ever ischaemic stroke: a pleiotropic effect of statins or a beneficial effect of hypercholesterolemia? BMC Neurol 2010;10: 47.
-9 Adams HP Jr, Bendixen BH, Kappelle LJ, Biller J, Love BB, Gordon DL, Marsh EE 3rd: Classification of subtype of acute ischemic stroke. Definitions for use in a multicenter clinical trial. TOAST. Trial of Org 10172 in Acute Stroke Treatment. Stroke 1993;24:35-41.

10 Kushner FG, Hand M, Smith SC Jr, King SB 3rd, Anderson JL, Antman EM, Bailey SR, Bates ER, Blankenship JC, Casey DE Jr, Green LA, Hochman JS, Jacobs AK, Krumholz HM, Morrison DA, Ornato JP, Pearle DL, Peterson ED, Sloan MA, Whitlow PL, Williams DO: 2009 focused updates: ACC/ AHA guidelines for the management of patients with ST-elevation myocardial infarction (updating the 2004 guideline and 2007 focused update) and ACC/AHA/SCAI guidelines on percutaneous coronary intervention (updating the 2005 guideline and 2007 focused update) a report of the American College of Cardiology Foundation/ American Heart Association Task Force on Practice Guidelines. J Am Coll Cardiol 2009; 54:2205-2241. 
11 Tanne D, Kasner SE, Demchuk AM, KorenMorag N, Hanson S, Grond M, Levine SR: Markers of increased risk of intracerebral hemorrhage after intravenous recombinant tissue plasminogen activator therapy for acute ischemic stroke in clinical practice: the multicenter rt-PA stroke survey. Circulation 2002;105:1679-1685.

-12 Tsivgoulis G, Frey JL, Flaster M, Sharma VK, Lao AY, Hoover SL, Liu W, Stamboulis E, Alexandrov AW, Malkoff MD, Alexandrov AV: Pre-tissue plasminogen activator blood pressure levels and risk of symptomatic intracerebral hemorrhage. Stroke 2009;40: 3631-3634.
13 Miedema I, Uyttenboogaart M, Koopman K, De Keyser J, Luijckx GJ: Statin use and functional outcome after tissue plasminogen activator treatment in acute ischaemic stroke. Cerebrovasc Dis 2010;29:263-267.

14 Montaner J: Cholesterol measured before stroke thrombolysis is not associated with tissue plasminogen activator-related hemorrhagic transformation. Stroke 2008;39:e6.

15 Martinez-Ramirez S, Delgado-Mederos R, Marín R, Suárez-Calvet M, Sáinz MP, Alejaldre A, Vidal-Jordana A, Martí-Vilalta JL, Martí-Fàbregas J: Statin pretreatment may increase the risk of symptomatic intracranial haemorrhage in thrombolysis for ischemic stroke: results from a case-control study and a meta-analysis. J Neurol 2012;259:111-118.
6 Wahlgren N, Ahmed N, Eriksson N, Aichner F, Bluhmki E, Davalos A, Erila T, Ford GA, Grond M, Hacke W, Hennerici MG, Kaste M, Kohrmann M, Larrue V, Lees KR, Machnig T, Roine RO, Toni D, Vanhooren G: Multivariable analysis of outcome predictors and adjustment of main outcome results to baseline data profile in randomized controlled trials: Safe Implementation of Thrombolysis in Stroke-Monitoring Study (SITS-MOST). Stroke 2008;39:3316-3322.

17 http://clinicaltrials.gov/ct2/show/ NCT01073007. 